\title{
Life during COVID-19: A pandemic of silence
}

\section{Kimberlyn Maravet Baig-Ward, MD, PhD}

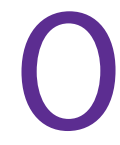
ur world has radically changed during the coronavirus disease 2019 (COVID-19) crisis, and this impact has quickly transformed many lives. Whether you're on the front lines of the COVID-19 pandemic or waiting in eager anticipation to return to practice, there is no denying that a few months ago we could never have imagined the health care and humanitarian crisis that is now before us. While we are united in our longing for a better time, we couldn't be further apart socially and emotionally ... and I'm not just talking about 6 feet.

One thing that has been truly striking to me is the silence. While experts have suggested there is a "silent pandemic" of mental illness on the horizon, ${ }^{1} I^{\prime}$ ve been struck by the actual silence that exists as we walk through our stores and neighborhoods. We're not speaking to each other anymore; it's almost as if we're afraid to make eye contact with one another.

Humans are social creatures, and the isolation that many people are experiencing during this pandemic could have detrimental and lasting effects if we don't take action. While I highly encourage and support efforts to employ social distancing and mitigate the spread of this illness, I'm increasingly concerned about another kind of truly silent pandemic brewing beneath the surface of the COVID-19 crisis. Even under the best conditions, many individuals with posttraumatic stress disorder, depression, anxiety, bipolar disorder, schizophrenia, and other psychiatric disorders may lack adequate social interaction and experience feelings of isolation. These individuals need connection-not silence.
What happens to people who already felt intense isolation before COVID-19 and may have had invaluable lifelines cut off during this time of social distancing? What about individuals with alcohol or substance use disorders, or families who are sheltered in place in unsafe or violent home conditions? How can they reach out in silence? How can we help?

\section{Fostering human connection}

To address this, we must actively work to engage our patients and communities. One simple way to help is to acknowledge the people you encounter. Yes, stay 6 feet apart, and wear appropriate personal protective equipment. However, it is still OK to smile and greet someone with a nod, a smile, or a "hello." A genuine smile can still be seen in someone's eyes. We need these types of human connection, perhaps now more than ever before. We need each other.

Most importantly, during this time, we need to be aware of individuals who are most at risk in this silent pandemic. We can offer our patients appointments via video conferencing. We can use texting, e-mail, social media, phone calls, and video conferencing to check in with our families, friends, and neighbors. We're at war with a terrible foe, but let's not let the human connection become collateral damage.

\section{Reference}

1. Galea S, Merchant RM, Lurie N, et al. The mental health consequences of COVID-19 and physical distancing: the need for prevention and early intervention [published online April 10, 2020]. JAMA Intern Med. 2020. doi: 10.1001/ jamainternmed.2020.1562.

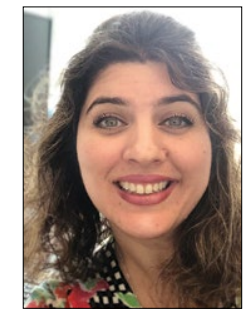

Dr. Baig-Ward is a PGY-1 Psychiatry Resident, Department of Psychiatry, UT Southwestern Medical Center, Dallas, Texas.

\section{Disclosure}

The author reports no financial relationships with any companies whose products are mentioned in this article, or with manufacturers of competing products.

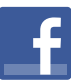

Discuss this article at www.facebook.com/ MDedgePsychiatry 